\title{
Guanylate-binding protein 2 regulates Drp1-mediated mitochondrial fission to suppress breast cancer cell invasion
}

\author{
Juan Zhang ${ }^{\star, 1,5}$, Yu Zhang ${ }^{2,5}$, Wenshuang Wu ${ }^{3,5}$, Fang Wang ${ }^{3}$, Xinyu Liu ${ }^{3}$, Guanghou Shui ${ }^{4}$ and Chunlai Nie ${ }^{\star, 1,3}$
}

Guanylate-binding protein 2 (GBP2) is a member of the large GTPase superfamily that is strongly induced by interferon- $\gamma$ (IFN- $\gamma$ ). Although the biochemical characteristics of GBP2 have been reported in detail, its biological function has not been thoroughly elucidated to date. To the best of our knowledge, this study presents the first demonstration that GBP2 inhibits mitochondrial fission and cell metastasis in breast cancer cells both in vitro and in vivo. Our previous work demonstrated that dynamin-related protein 1 (Drp1)-dependent mitochondrial fission has a key role in breast cancer cell invasion. In this study, we demonstrate that GBP2 binds directly to Drp1. Elimination of Drp1 by shRNA or Mdivi-1 (a Drp1-specific inhibitor) suppressed GBP2's regulatory function. Furthermore, GBP2 blocks Drp1 translocation from the cytosol to mitochondria, thereby attenuating Drp1-dependent mitochondrial fission and breast cancer cell invasion. In summary, our data provide new insights into the function and molecular mechanisms underlying GBP2's regulation of breast cancer cell invasion.

Cell Death and Disease (2017) 8, e3151; doi:10.1038/cddis.2017.559; published online 26 October 2017

Guanylate-binding proteins (GBPs) were originally identified as proteins induced by IFN- $\gamma$ in human fibroblasts. ${ }^{1}$ These proteins belong to the superfamily of large GTPases related to dynamin and have similar structural and biochemical properties. Among the seven members of the human GBP family, ${ }^{2,3}$ GBP1 and GBP2 are mostly induced in cells or tissues upon exposure to IFN- $\gamma .{ }^{4}$ GBP1 can mediate the inhibitory effects of inflammatory cytokines on proliferation, migration and invasion of endothelial cells and epithelial tumor cells. ${ }^{4-8}$ In addition, GBP1 expression in colorectal carcinoma have been associated with reduced tumor aggressiveness and improved prognosis. $^{5,9}$ Similarly, GBP2 is postulated as a possible control factor in tumor cell proliferation and spreading. ${ }^{10,11}$ Increased GBP2 expression is also associated with a better prognosis in breast cancer and may have a role in T-cell defense against breast cancer. ${ }^{12}$ Interestingly, GBP2 expression in NIH 3T3 fibroblasts inhibited Rac activation and matrix metalloproteinase- 9 expression, ${ }^{13}$ suggesting a possible role for GBP2 in regulating cancer metastasis. However, the targets and molecular mechanisms of GBP2's regulation of cancer metastasis remain largely unknown.

Mitochondria exist as dynamic networks maintained by two opposing processes: fission and fusion, ${ }^{14}$ primarily regulated by dynamin-related protein 1 (Drp1) and mitofusins (Mfns), ${ }^{14,15}$ respectively. Mitochondrial fission or fusion dysfunction deregulates key cellular processes, potentially contributing to tumorigenesis. ${ }^{16}$ We previously reported that Drp1-dependent mitochondrial fission is critical for breast cancer cell invasion. ${ }^{17}$ As breast cancer metastasis is a highly complex process regulated by many factors, we reason that there may be additional factors participating in mitochondrial dynamics that regulate breast cancer metastasis. In the present study, we found that GBP2 interacts with Drp1 and blocks translocation of Drp1 to mitochondria, thereby attenuating Drp1-dependent mitochondrial fission and invasion of breast cancer cells. Thus GBP2 may represent a new therapeutic target to suppress breast cancer metastasis through attenuation of Drp1-dependent mitochondrial fission.

\section{Results}

GBP2 expression inhibits invasion and mitochondrial elongation in breast cancer cells. To investigate whether GBP2 modulates cancer metastasis, GFP-tagged GBP2 or GFP vector were transfected into the indicated metastatic breast cancer cells (Supplementary Figure 1a). Transwell assays $^{18}$ demonstrated that cells expressing GFP-tagged GBP2 exhibited a decrease in invasive abilities compared with their control cells expressing GFP alone (Figure 1a). Moreover, animal experiments revealed that most control mice with mammary tumors developed massive lung metastases, but GBP2-expressing mice had significantly fewer lung

\footnotetext{
${ }^{1}$ Center for Core Facility and Advanced Technologies, Institute of Genetics and Developmental Biology, Chinese Academy of Sciences, Beijing 100101, China; ${ }^{2}$ Department of Oncology, Guizhou People's Hospital, Guizhou 550002, China; ${ }^{3}$ State Key Laboratory of Biotherapy and Cancer Center, West China Hospital, Sichuan University and Collaborative Innovation Center for Biotherapy, Chengdu 610041, China and ${ }^{4}$ State Key Laboratory of Molecular Developmental Biology, Institute of Genetics and Developmental Biology, Chinese Academy of Sciences, Beijing 100101, China

*Corresponding author: J Zhang, Center for Core Facility and Advanced Technologies, Institute of Genetics and Developmental Biology, Chinese Academy of Sciences, Beijing 100101, China. Tel: +86 10 64806525; Fax: +86 10 64806524; E-mail: zhangjuan@genetics.ac.cn or C Nie, State Key Laboratory of Biotherapy/Collaborative Innovation Center of Biotherapy, Sichuan University, 17\# People's South Road, Chengdu, Sichuan Province 610041, China. Tel: +86 2885164063 ; Fax: +86 28 85164059; E-mail: niecl1022@hotmail.com; niecl1022@scu.edu.cn

${ }^{5}$ These authors contributed equally to this work.

Received 04.5.17; revised 13.9.17; accepted 20.9.17; Edited by G Raschella
} 
a

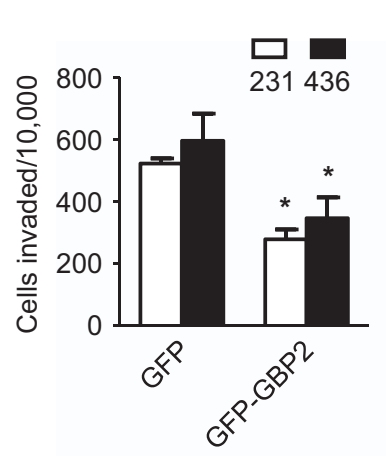

b

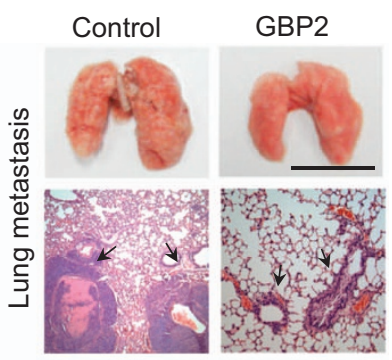

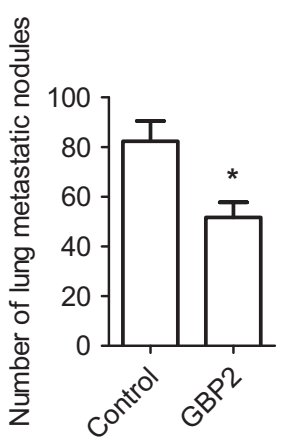

\section{C}

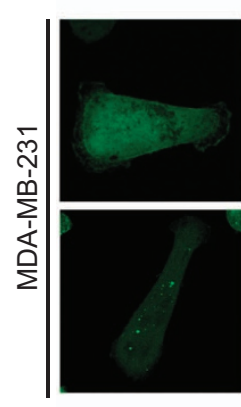

Mitochondria
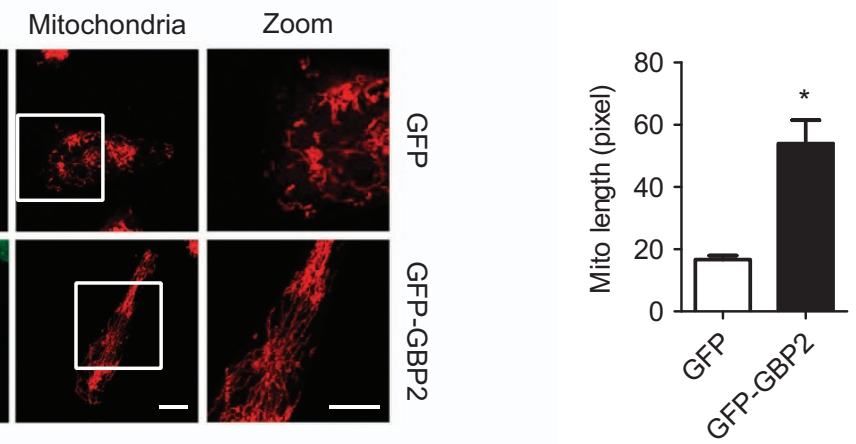

d

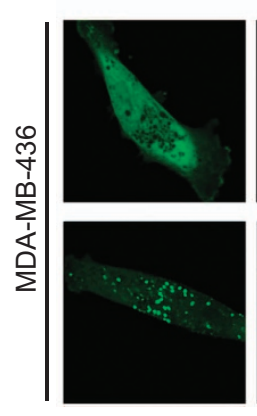

Mitochondria
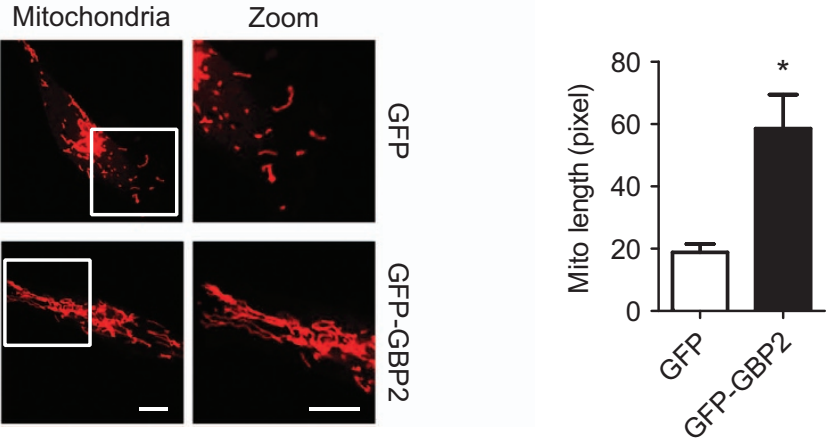

Figure 1 Expression of GBP2 inhibits invasion and induces mitochondrial elongation of breast cancer cells. (a) Overexpression of GFP-tagged GBP2 inhibited invasion of breast cancer MDA-MB-231 and MDA-MB-436 cells. Data shown are mean \pm S.E.M. $(n=4),{ }^{*} P<0.05$. (b) Upregulation of GBP2 in MDA-MB-231 cells decreases the metastasis ability in mice. Left panel: Upper is the representative imaging of lung tissues from mouse model of metastasis. Bars, $1 \mathrm{~cm}$; Below is the representative hematoxylin and eosin-stained lung sections exhibiting metastasis in representative mice, magnification of the histopathological sections, $\times 50$. Right panel: Nodules rich in densely packed cells, as indicated by the black arrows, were quantified as tumor nodules. Values represent the mean \pm S.E.M. $(n=8-11)$, ${ }^{*} P<0.05$. The representative images of (c) MDAMB-231 cells and (d) MDA-MB-436 cells expressing GFP or GFP-GBP2 (green). Mitochondria were visualized with MitoTracker Red. Right panel is the quantification of mitochondrial lengths in MDA-MB-231 and MDA-MB-436 cells. Scale bar, $10 \mu \mathrm{m}$. Data shown are mean \pm S.E.M. $n=29-42$ randomly selected cells, ${ }^{*} P<0.05$

metastases (Figure 1b). Interestingly, GBP2 expression did not increase apoptosis or cell death (Supplementary Figures $1 b$ and $c$ ). The expression of GBP1 had little effect on cell invasion under the same conditions (data not shown).

Given that breast cancer cell metastasis can be regulated by mitochondrial dynamics, we tested whether GBP2 could alter mitochondrial networks. As shown in Figures 1c and d (left panels), GFP was distributed throughout the cytoplasm, whereas tagged GBP2 was distributed in specific subcellular regions, as described before. ${ }^{19}$ Expression of GBP2 led mitochondria to be more filamentous and increased mitochondrial length in the indicated cells (Figures 1c and d, right panel). We also transfected GFP or GFP-tagged GBP1 vector into the indicated cells to see whether GBP1 affects mitochondrial dynamics. We found that GBP1 expression had little effect on mitochondrial elongation (Supplementary Figure 2a).

We then used IFN- $\gamma$ to induce endogenous GBP2 expression in cells. ${ }^{2}$ As shown in Supplementary Figure $2 \mathrm{~b}$, IFN- $\gamma$ efficiently induced GBP2 expression in cells. Furthermore, Figure 2 a shows that treatment with IFN- $\gamma$ reduced invasion of the indicated cells. It should be noted that IFN- $\gamma$ treatment at a certain concentration $(50 \mathrm{ng} / \mathrm{ml})$ did not result in the change of cell apoptosis (Figure $2 b$ ) or cell viability (Figure $2 c$ ) in cells.

Confocal images show that treatment with recombinant IFN- $\gamma$ resulted in time-dependent mitochondrial elongation in 

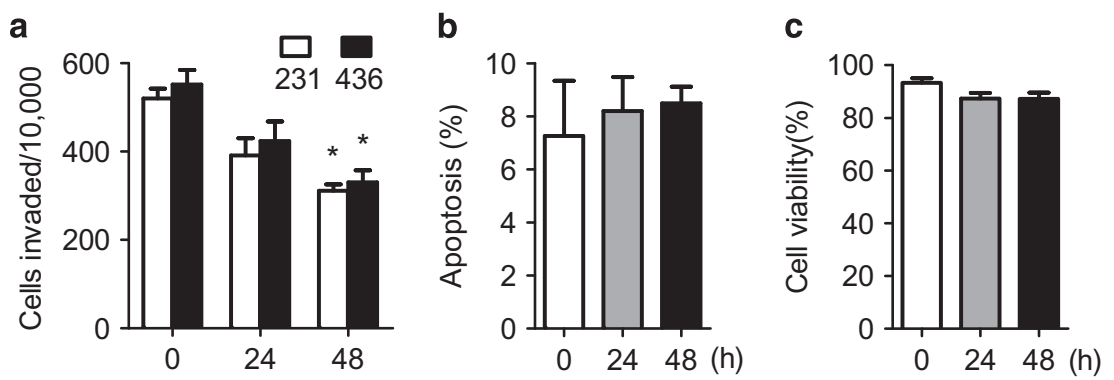

d
IFN-Y

(50ng/ml)

Oh
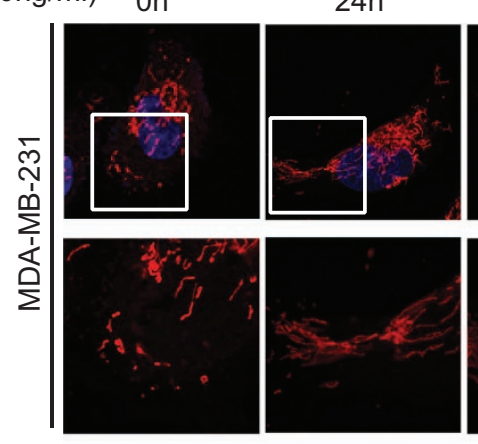

e

IFN-Y

(50ng/ml)

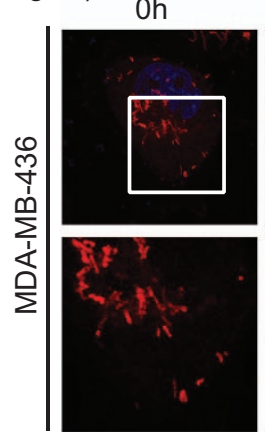

$24 \mathrm{~h}$

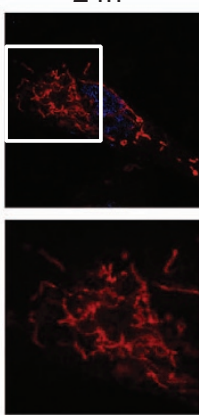

$48 \mathrm{~h}$

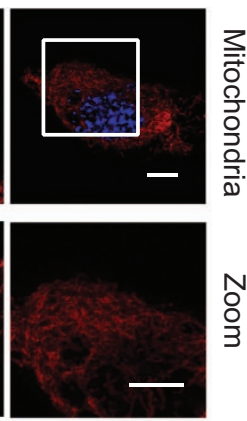

$48 \mathrm{~h}$

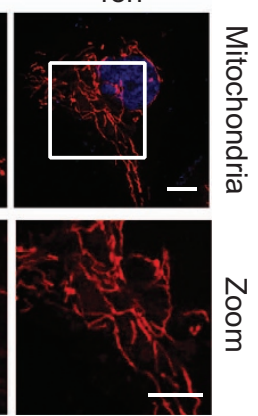

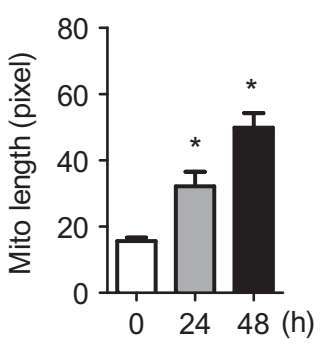

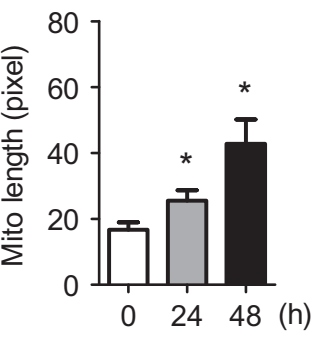

Figure 2 IFN- $\gamma$ treatment led to inhibition invasion and mitochondrial elongation of breast cancer cell. (a) IFN- $\gamma(50 \mathrm{ng} / \mathrm{ml})$ treatment for 24 and $48 \mathrm{~h}$ inhibits invasive abilities of breast cancer MDA-MB-231 and MDA-MB-436 cells. Data shown are mean \pm S.E.M. $(n=4),{ }^{*} P<0.05$. (b) IFN- $\gamma$ treatment for 24 and 48 h could not induce cell apoptosis and (c) initiates cell viability in MDA-MB-231 cells. (d) MDA-MB-231 and (e) MDA-MB-436 cells were treated with $50 \mathrm{ng} / \mathrm{ml}$ IFN- $\gamma$ for 24 and $48 \mathrm{~h}$. Left panel, Cells were stained with Mitotracker Red and visualized under confocal microscope. Scale bar, $10 \mu \mathrm{m}$. Right panels, Quantification of mitochondrial lengths. Data shown are mean \pm S.E.M., ${ }^{*} P<0.05$. $n=19-29$ randomly selected cells

the indicated cells (Figures $2 d$ and e, left panels). The average length of mitochondria was increased after IFN- $\gamma$ treatment (Figures 2d and e, right panels).

As many proteins respond to IFN- $\gamma$ stimulation, we needed to determine whether the effects of IFN- $\gamma$ on invasion and mitochondrial dynamics in breast cancer cells were dependent on induction of GBP2, rather than other inducible proteins. We next transfected the indicated cells with GBP2 shRNA to deplete IFN- $\gamma$-induced GBP2 (Figures $3 a$ and $b$ ). Inhibition of GBP2 expression restrained the effect of IFN $-\gamma$ on the invasive abilities of cells (Figure 3c). GBP1 protein was also expressed in the indicated cells with IFN- $\gamma$ treatment (Figures $3 d$ and e). ${ }^{1}$ GBP1 shRNA in the indicated cells efficiently reduced GBP1 expression in response to IFN- $\gamma$ treatment. However, GBP1 depletion had little effect on the invasive abilities of the treated cells (Figure 3f). Moreover, GBP2 depletion abolished IFN- $\gamma$ induced mitochondrial elongation (Figure $3 \mathrm{~g}$ ), while GBP1 depletion failed to change elongated mitochondria induced by IFN- $\gamma$ (Figure 3h). Taken together, our data suggest that GBP2 specifically reduces invasion and is involved in regulating mitochondrial dynamics in metastatic breast cancer cells.

Drp1 is a cellular binding factor of GBP2. Next, we characterized the molecular mechanism of GBP2's participation in cell invasion and mitochondrial dynamics. Previous work demonstrated that Drp1-dependent mitochondrial fission regulates metastasis of breast cancer cells. ${ }^{17}$ We found that IFN- $\gamma$ treatment resulted in mitochondrial elongation and 
a

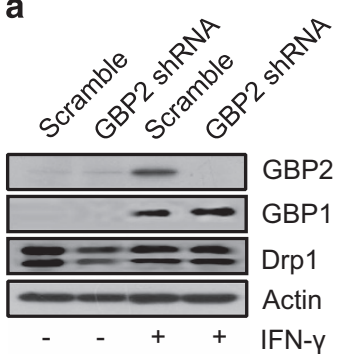

d

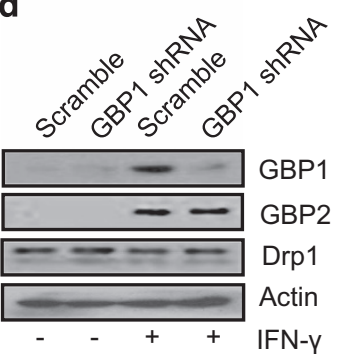

b

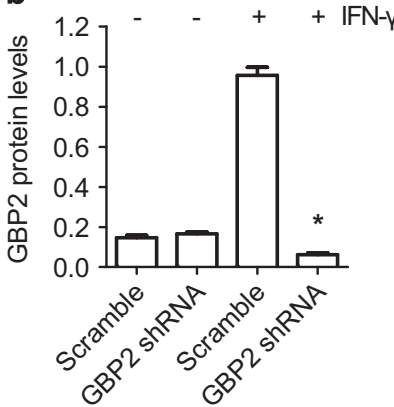

e

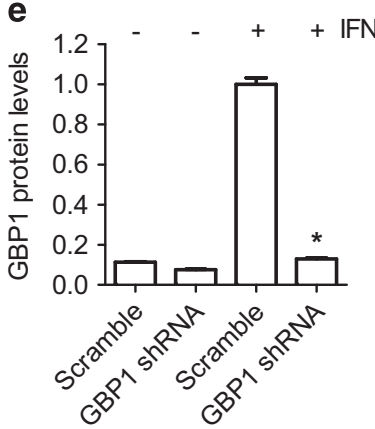

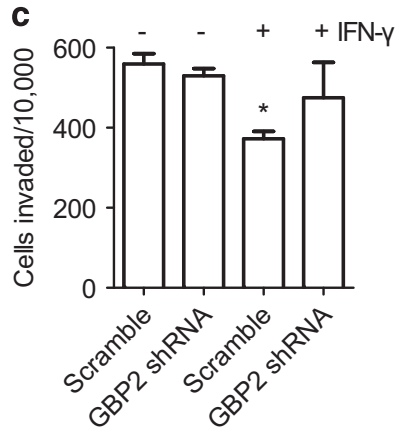

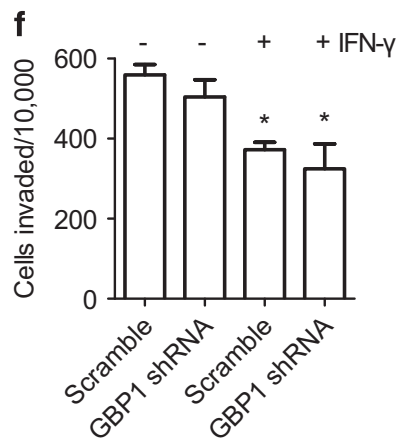

g
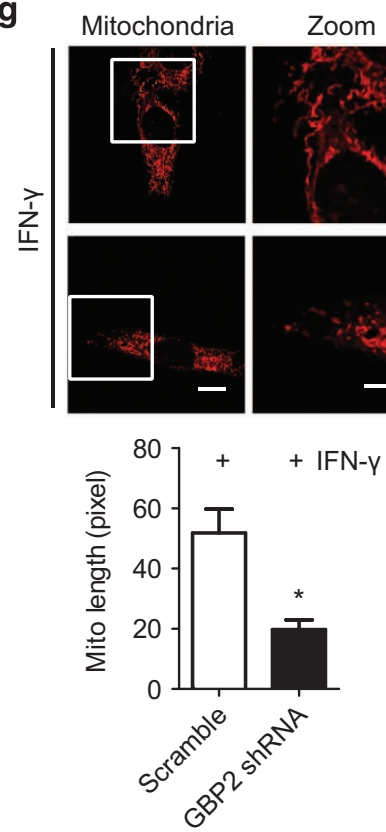

h
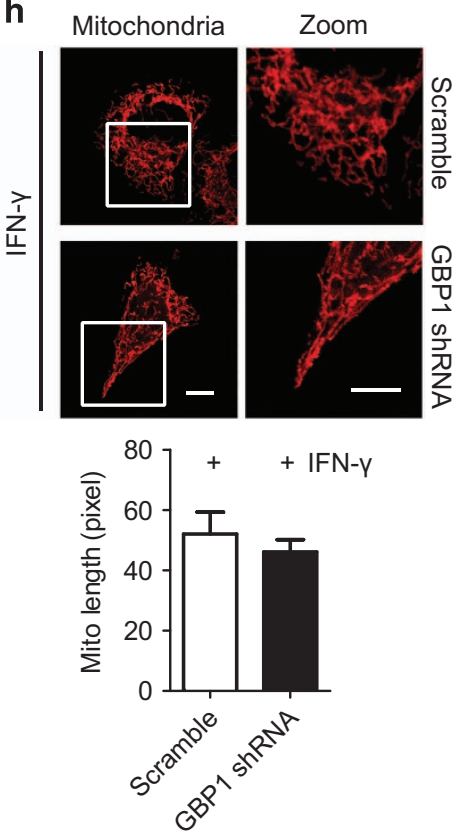

Figure 3 GBP2 is essential for IFN- $\gamma$-induced mitochondrial elongation and inhibition of breast cancer cell invasion. (a) IFN- $\gamma$-induced GBP2 in MDA-MB-231 cells was depleted by GBP2 shRNA but not scramble shRNA. A blot representative of three experiments is shown. (b) The histogram shows the mean GBP2 band density, which was measured and normalized to $\beta$-actin \pm S.E.M., $n=3,{ }^{*} P<0.05$. (c) GBP2 depletion abolished IFN- $\gamma$-induced inhibition of MDA-MB-231 cell invasion. Data shown are mean \pm S. E.M. $(n=4),{ }^{*} P<0.05$. (d) GBP1 in MDA-MB-231 was depleted by GBP1 shRNA but not scramble shRNA. A blot representative of three experiments is shown. (e) The histogram shows the mean GBP1 band density, which was measured and normalized to $\beta$-actin \pm S.E.M., $n=3,{ }^{*} P<0.05$. (f) GBP1 depletion had little effect on IFN- $\gamma$-induced inhibition of MDA-MB-231 cell invasion. Data shown are mean + S.E.M. $(n=4)$. (g) Upper panel, the representative images of MDA-MB-231 cells transfected with the pSliencer2.1 null vector or vector expressing GBP2 shRNA. Mitochondria were visualized with MitoTracker Red. Scale bar, $10 \mu \mathrm{m}$. Lower panel, data shown in the upper panel are the average mitochondrial lengths in 19-22 randomly selected MDA-MB-231 cells. Error bars, S.E.M., ${ }^{*} P<0.05$. (h) Upper panel, the representative images of MDA-MB-231 cells transfected with the pSliencer-2.1 null vector or vector expressing GBP1 shRNA. Scale bar, $10 \mu \mathrm{m}$. Lower panel, data shown in the upper panel are the average mitochondrial lengths in 19-22 randomly selected MDA-MB-231 cells. Error bars, S.E.M., ${ }^{*} P<0.05$ 
induction of GBP2 expression, with little change in Drp1 expression or Mfn1 and Mfn2 in the indicated cells (Supplementary Figure 2b). It is possible that GBP2 interacts with Drp1. To test this hypothesis, we first performed coimmunoprecipitation assays to identify whether GBP2 can bind to Drp1 in whole-cell extracts of cells. As low expression levels of endogenous GBP2 in cells (Supplementary Figure $2 b$ ) would make it difficult to detect an interaction between GBP2 and Drp1, we employed exogenous expression of GBP2 as well as IFN- $\gamma$ treatment to induce endogenous GBP2. Indicated cells were transfected with Flag-GBP2 constructs. Co-immunoprecipitation revealed the presence of Drp1 in the Flag-GBP2 immunoprecipitate (Figure 4a). Meanwhile, Drp1 failed to co-precipitate with Flag-GBP1 (Supplementary Figure 2c). We also performed GST-GBP2 pull-down assays in the indicated cells. GSTGBP2 pull-down assays combined with western blotting analysis showed the presence of Drp1 in the pull-down fraction of GST-GBP2 but not in the GST control (Figure 4b). We then performed GST-GBP2 pull-down assays using the

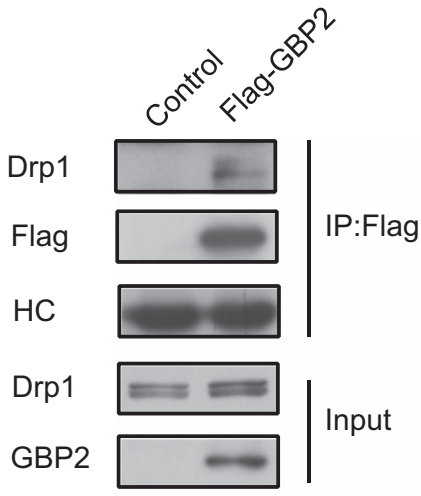

C IFN-Y $\lg \mathrm{G}$ anti-GBP2

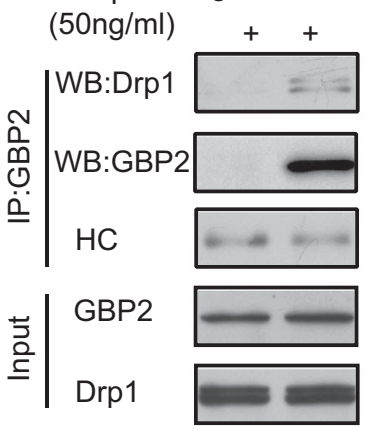

b

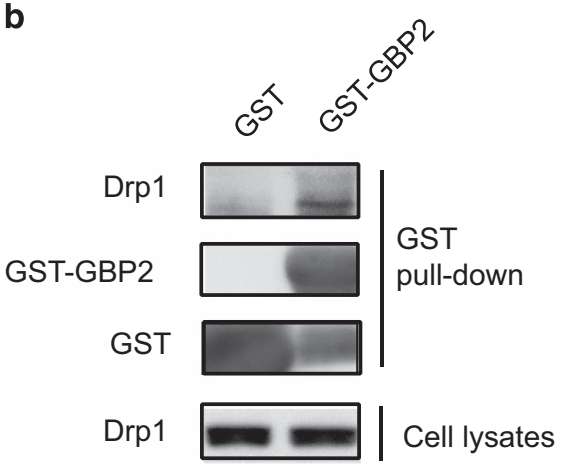

d

IFN-y $\quad \lg G$ anti-Drp1

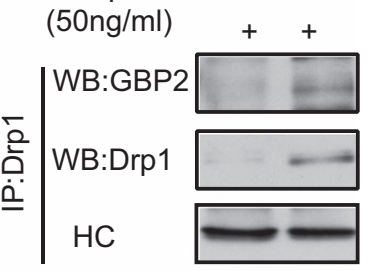

\begin{tabular}{l|ll} 
글 & GBP2 & $\square$ \\
Drp1 & $\square=$
\end{tabular} e

Drp1-CFP
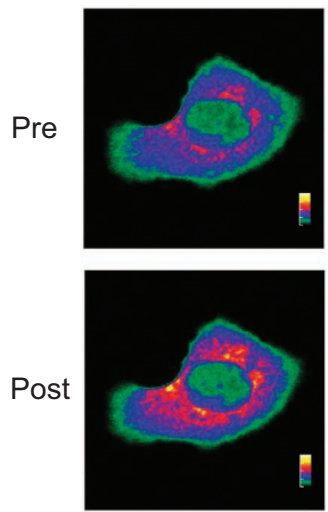

YFP-GBP2
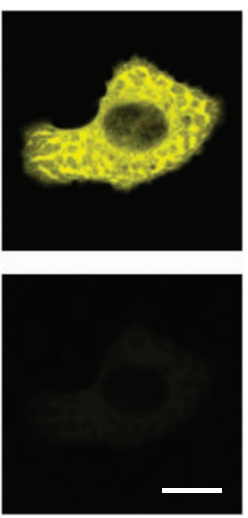
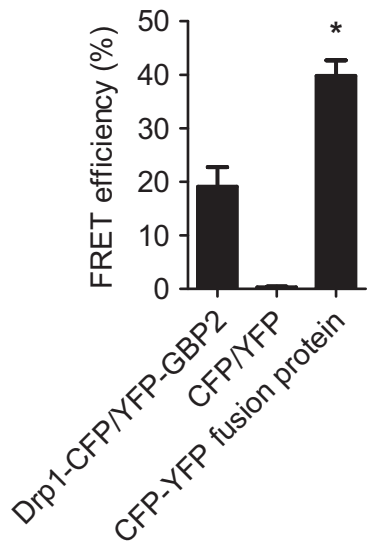

Figure 4 Identification of Drp1 as a GBP2 interaction protein in breast cancer cells. (a) Immunoprecipitation of the extracts from control MDA-MB-231 cells or cells expressing Flag-tagged GBP2 using anti-Flag antibody, followed by western blotting analysis with antibodies against the Flag or Drp1. Heavy chain (HC) of anti-Flag antibody was used as a loading control. Rabbit lgG was used as a control. The presence of GBP2 and Drp1 was detected by western blotting. (b) Western blotting analysis of GST and GST-GBP2 precipitates of MDA-MB-231 cell lysates using anti-Drp1 or anti-GST antibody. (c and d) IFN- $\gamma$-induced GBP2 interacts with Drp1 in MDA-MB-231 cells. Co-immunoprecipitation assays of IFN- $\gamma$-treated MDA-MB-231 cell lysates using anti-GBP2 (c) or anti-Drp1 antibody (d). (e) Left panel, fluorescent images of MDA-MB-231 cells co-transfected with Drp1CFP and YFP-GBP2 in CFP and YFP channels prephotobleaching and postphotobleaching of YFP fluorescence. Scale bar, $10 \mu \mathrm{m}$. Right panel, The histogram shows the FRET efficiency from CFP to YFP in the cells transfected with Drp1-CFP and YFP-GBP2, CFP and YFP or CFP-YFP fusion protein. Data shown are mean \pm S.E.M. $(n=15)$, ${ }^{*} P<0.05$ 
a

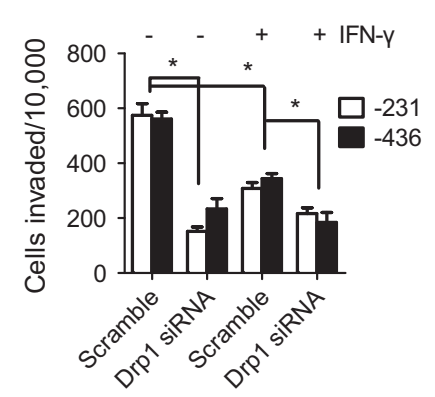

c

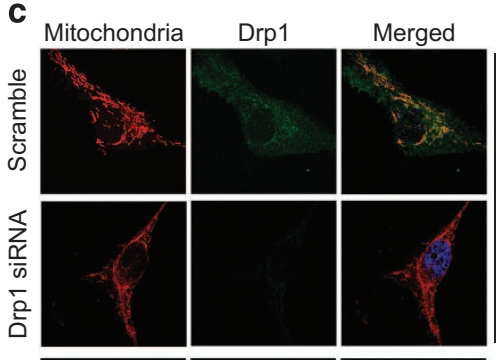

क
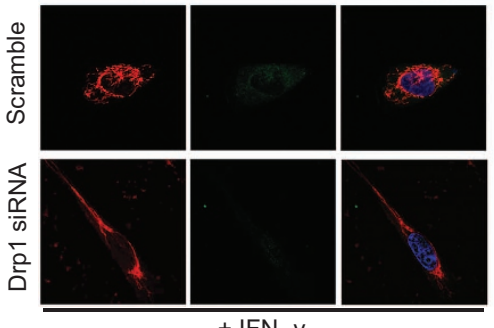

+ IFN- $y$

e

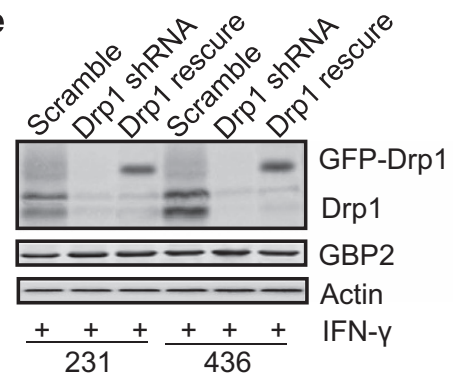

g

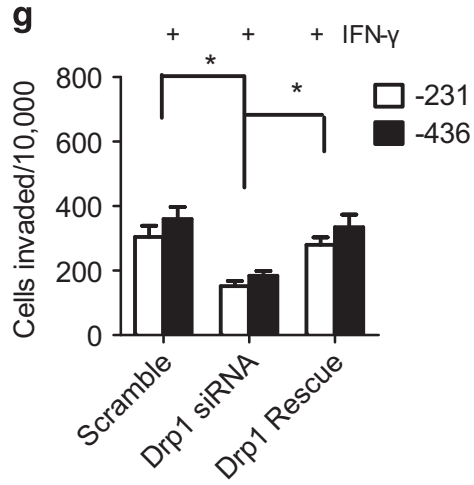

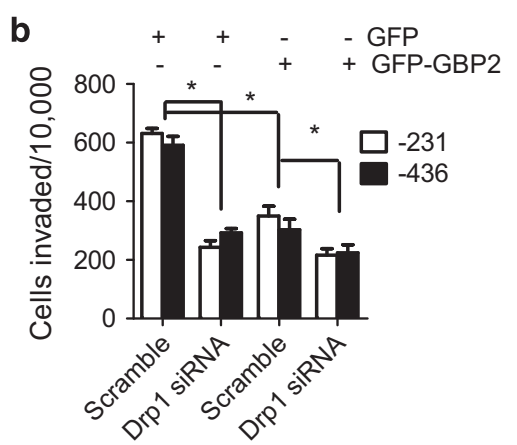

d

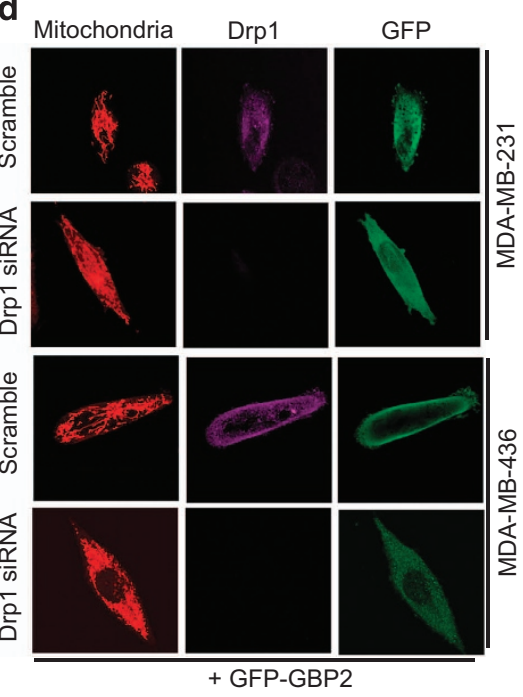

f
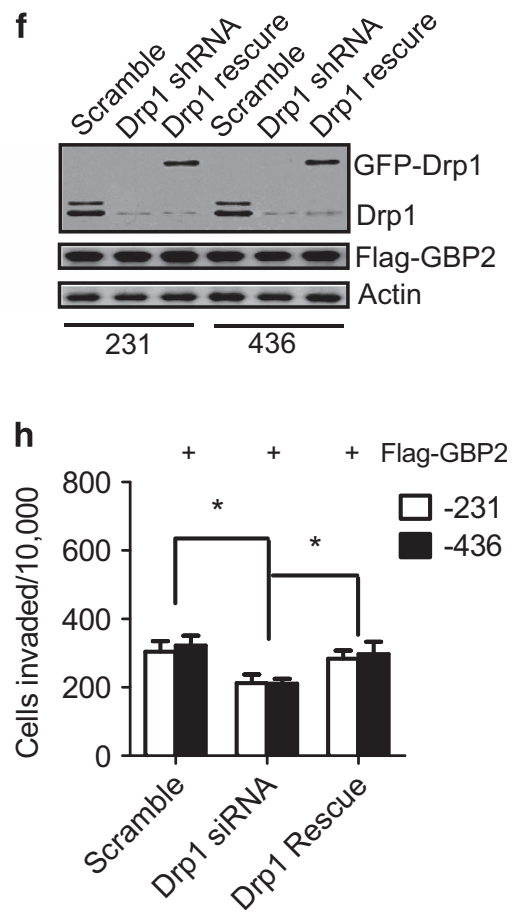
Figure 5 Drp1 depletion inhibits GBP2 mediated cell invasion and mitochondrial fission. Knockdown of endogenous Drp1 inhibits invasion abilities of breast cancer MDAMB-231 and MDA-MB-436 cells with (a) IFN- $\gamma$ treatment or (b) transfected with GFP-GBP2 or GFP as control. The histogram shows cell invasion. Data shown are mean \pm S.E.M. $(n=4)$, ${ }^{*} P<0.05$. (c and d) Representative confocal images of MDA-MB-231 cells (upper) and MDA-MB-436 cells (lower) with IFN- $\gamma$ treatment or GFP-GBP2 expression, transfected with scramble or Drp1 shRNA and stained with MitoTracker Red, show endogenous expression of Drp1 and mitochondrial morphology; green shows exogenous GBP2 expression. Scale bar, $10 \mathrm{~mm}$. (e and f) A GFP-tagged Drp1 mutant, insensitive to Drp1 shRNA, was expressed in Drp1-silenced breast cancer cells with IFN- $\gamma$ treatment or Flag-GBP2 expression for $48 \mathrm{~h}$, and cells were then collected for western blotting analysis of Drp1 expression. ( $\mathbf{g}$ and $\mathbf{h}$ ) As described in panels (e and $\mathbf{f}$ ), cells were collected for transwell invasion assays. $n=4$, mean \pm S.E.M. ${ }^{*} P<0.05$

indicated cell lysates combined with mass spectrometric analysis. Drp1 was indeed identified in GST-GBP2 precipitate but not in control samples in two independent mass spectrometric experiments (Supplementary Figures $3 a$ and b). Coimmunoprecipitation assays with IFN- $\gamma$-treated cell lysates showed the presence of Drp1 in the GBP2 immunoprecipitate (Figure 4c) and the presence of GBP2 in the Drp1 immunoprecipitate (Figure 4d). In contrast, no GBP2 or Drp1 was precipitated when rabbit lgG was used. Together, these results suggest that GBP2 interacts with endogenous Drp1 in breast cancer cells.

To validate our findings that GBP2 interacts physically with Drp1, we performed fluorescence resonance energy transfer (FRET) analysis as described before ${ }^{20}$ to validate whether GBP2 interacts directly with Drp1. Indicated cells were cotransfected with Drp1-CFP and YFP-GBP2, and the fluorescent intensity of the donor Drp1-CFP or the acceptor YFPGBP2 was measured before and after photobleaching by a laser beam. The fluorescent intensity of Drp1-CFP was remarkably increased after the fluorescence of YFP-GBP was completely quenched (Figure 4e, left panel). The energy transfer efficiency from Drp1-CFP to YFP-GBP2 was $19.1 \pm 3.7 \%$ (Figure 4e, right panel), suggesting a direct interaction between Drp1-CFP and YFP-GBP2. In contrast, little energy transfer was detected in cells co-transfected with CFP and YFP proteins. As a positive control, the energy transfer efficiency was $40.3 \pm 2.8 \%$ within a CFP-YFP fusion protein. Collectively, our data demonstrate that Drp1 and GBP2 have a physical interaction in breast cancer cells.

Previous reports have shown that phosphorylation of Ser 637 in Drp1 promotes mitochondrial elongation. ${ }^{21,22}$ However, the phosphorylation of Ser 616 promotes mitochondrial fragmentation. ${ }^{23,24}$ To identify whether GBP2 has a role in regulating phosphorylation of Drp1, exogenous GBP2 was expressed in the indicated cells, and the phosphorylation of Drp1 was determined by western blotting. As shown in Supplementary Figures $3 c$ and d, GBP2 had little effect on either Ser 637 or Ser 616 phosphorylation status of Drp1, suggesting that GBP2 does not regulate the function of Drp1 by modulating its phosphorylation.

GBP2 regulation of cell invasion and mitochondrial fission depends on Drp1. Next, we addressed the biological significance of the interaction between GBP2 and Drp1. Depletion of Drp1 with shRNA was utilized to see whether it blocks cell invasion regulated by GBP2. We found that Drp1 shRNA had little effect on GBP2 expression in the indicated cells treated with IFN- $\gamma$ or overexpression of GBP2 (Supplementary Figures $4 a-d$ ). However, it was noteworthy that Drp1 depletion reduced invasion in cells treated with IFN$\gamma$ or overexpression of GBP2 (Figures $5 a$ and b). Meanwhile,
Drp1 depletion decreased mitochondrial fission and promoted elongation of cells regardless of IFN- $\gamma$-induced GBP2 expression or overexpression of GBP2 (Figures $5 c$ and d). To rule out 'off-target' effects of shRNA, we next carried out rescue experiments by re-expressing GFP-tagged Drp1 with a mutation that is insensitive to Drp1 shRNAs in Drp1silenced cells (Figures $5 \mathrm{e}$ and f). GFP-Drp1 efficiently restored invasion of the Drp1-silenced cells with GBP2 expression induced by IFN- $\nu$ (Figure $5 \mathrm{~g}$ ) or transfected with Flag-GBP2 (Figure 5h). These results suggest that GBP2 is an upstream regulator of Drp1-dependent cell invasion and regulates cell invasion and mitochondrial fission through Drp1.

To determine GBP2 dependence on Drp1 to regulate cell invasion of breast cancer cells, we treated cells with Mdivi-1, a Drp1-specific inhibitor that allows for unopposed fusion. ${ }^{25}$ As shown in Supplementary Figure 4e, Mdivi-1 treatment destroyed GBP2-Drp1 binding and inhibited invasion of cells with or without IFN- $\gamma$-induced GBP2 expression (Supplementary Figure 4f). Moreover, GBP2 expression was synergistic with Mdivi-1 in further reducing cell invasion, which suggests that both GBP2 and Mdivi-1 regulate cell invasion through targeting Drp1. These results further indicate that GBP2-regulated cell invasion and mitochondrial fission is dependent on Drp1.

GBP2 K51A mutation blocks interaction with Drp1 and inhibition of mitochondria fission. To determine which structural domain of GBP2 is responsible for the interaction of GBP2 with Drp1, several truncated or mutated GBP constructs with a Flag tag (Figure 6a,Supplementary Figure 5a) were generated and expressed in the indicated cells. The interaction of these proteins with endogenous Drp1 was examined by CoIP experiments using anti-Flag antibody. As shown in Supplementary Figure $5 \mathrm{~b}$, deletion of N-terminal GTPase globular domain $\left(\mathrm{GBP} 2^{276-591}\right)$, C-terminal helical domain (GBP2 ${ }^{1-308}$ ) or N-terminal GTPase globular and middle connecting domains (GBP2 $\left.{ }^{308-591}\right)^{26}$ diminished GBP2 interaction with Drp1, indicating that the integrated structure of GBP2 is requisite for its interaction with Drp1. However, it is interesting that GBP ${ }^{\mathrm{K} 51 \mathrm{~A}}$, a GTPase-defective mutant, ${ }^{27}$ could inhibit interaction with Drp1, while GBP2 ${ }^{\mathrm{D} 103 \mathrm{~L} / \mathrm{D} 108 \mathrm{~L}}$, another GTPase-defective mutant, ${ }^{26,28}$ could still effectively interact with Drp1 (Figure 6b).

Further experiments revealed that overexpression of fulllength GBP2 or the GBP2 ${ }^{\mathrm{D} 103 \mathrm{~L} / \mathrm{D} 108 \mathrm{~L}}$ mutant led to elongation of mitochondria in cells (Figures $6 \mathrm{c}$ and $\mathrm{d}$ ). In contrast, GBP2 ${ }^{\mathrm{K} 51 \mathrm{~A}}$ expression had little effect on the length of mitochondria in cells, as well as the expression of GBP2 ${ }^{276-}$ 591, GBP2 ${ }^{1-308}$ or GBP2 ${ }^{308-591}$ mutants (Supplementary Figure $5 \mathrm{c}$ ). Moreover, the expression of $\mathrm{GBP} 2^{\mathrm{K} 51 \mathrm{~A}}$ mutant 
a

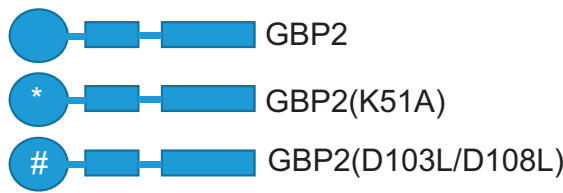

b

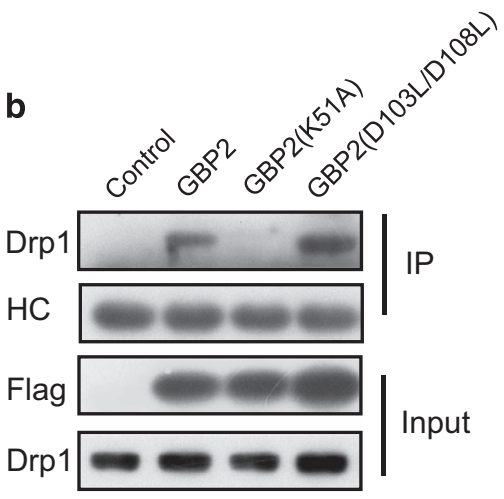

GBP2

C

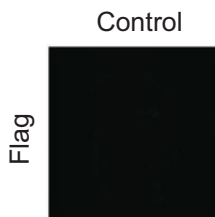

GBP2

GBP2(K51A) (D103L/D108L)
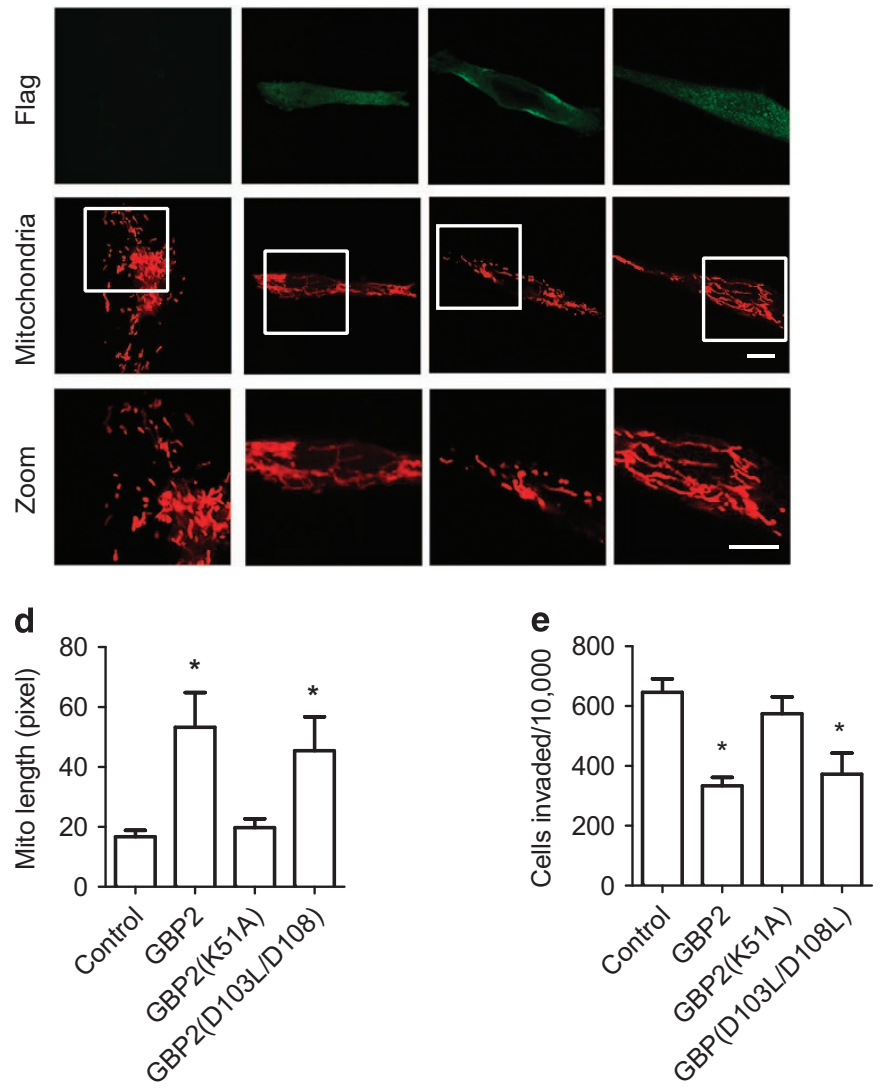

Figure 6 Domains of GBP2 are required for its interaction with Drp1 and inhibition of mitochondria fission. (a) Panel of GBP2 and its mutants. GBP2 ${ }^{\text {D103LD108L }}$, defective in hydrolysis from GTP to GMP; GBP2 ${ }^{\mathrm{K} 1 \mathrm{~A}}$, GTPase-defective mutant. (b) Cell lysates of MDA-MB-231 cells expressing Flag-GBP2, GBP2 mutants or empty vector as indicated were subjected to immunoprecipitation with anti-Flag antibody, followed by western blotting with Drp1 antibody. The heavy chain of immunoglobulins was used as loading control. (c) The confocal images of MDA-MB-231 cells expressing Flag-tagged GBP2, GBP2 mutants or empty vector. Mitochondria were visualized with Mitotracker red. Scale bar, $10 \mu \mathrm{m}$. (d) The length of mitochondria was quantified using Image-Pro Plus software. Data shown are mean \pm S.E.M. of $25-30$ randomly selected cells, ${ }^{*} P<0.05$. (e) The histogram shows cell invasion of MDA-MB-231 cells expressing Flag-tagged GBP2, GBP2 mutants or empty vector. Data shown are mean \pm S.E.M. $(n=4)$, ${ }^{*} P<0.05$

significantly rescued cell invasion, compared with the expression of GBP2 or the GBP2 ${ }^{\mathrm{D} 103 \mathrm{~L} / \mathrm{D} 108 \mathrm{~L}}$ mutant (Figure $6 \mathrm{e}$ ). $\mathrm{GBP}^{276-591}, \mathrm{GBP}^{1-308}$ or GBP2 $2^{308-591}$ mutant expression failed to block cell invasion (Supplementary Figure 5d).

These data reveal that Lysine 51 of GBP2 is critical for the interaction between GBP2 and Drp1, and every domain of GBP2 participates in binding with Drp1.
GBP2 blocks Drp1 translocation to the mitochondria and inhibits mitochondrial fission and cell invasion. It has been shown that translocation of Drp1 to the mitochondria is critical for its regulation of mitochondrial fission. ${ }^{29}$ It is possible that GBP2 suppresses mitochondrial fission and cell invasion via regulation of Drp1 translocation to mitochondria. To test this hypothesis, we performed subcellular 
fractionation assays using lysates of the indicated cells transfected with vector encoding Flag-tagged GBP2 or just the Flag tag. Western blotting shows that GBP2 is located predominately in the cytosol. There was no detectable GBP2 in the mitochondrial fraction, as described before. ${ }^{19}$ Drp1 was mainly located in the cytosol and marginally in the mitochondrial fraction (Figure $7 \mathrm{a}$, left panel), as described before. ${ }^{30}$ Compared with control Flag, overexpression of Flag-tagged GBP2 decreased the amount of Drp1 protein in the mitochondrial fraction by approximately $70 \%$, whereas the Drp1 level in the cytosolic fraction was increased (Figure 7a, right panel). Similarly, IFN- $\gamma$ treatment induced GBP2 expression and significantly decreased the amount of Drp1 protein in the mitochondrial fraction by $>50 \%$ (Figure $7 \mathrm{~b}$ ). In contrast, there was no change in the amount of Mfn1/2 in the mitochondrial fraction (data not shown). Meanwhile, the GBP2 mutant, GBP ${ }^{\mathrm{K} 51 \mathrm{~A}}$, which fails to bind Drp1, had little effect on Drp1 translocation (Supplementary Figure 6a) or mitochondrial fission and cell invasion (Figures 6d and e). Moreover, confocal microscopy revealed that upregulation of GBP2 by exogenous expression of GBP2 or IFN- $\gamma$ treatment altered subcellular localization of Drp1 (Figures 7c and d, left panel). Immuno-staining analysis shows that, in control cells or cells transfected with Flag protein, Drp1 (green) was distributed as puncta, often localized on mitochondrial tubules (indicated by MitoTracker red) (Figure 7c), and a similar observation was made in IFN- $\gamma$-treated cells (Figure 7d). This punctate Drp1 staining represents Drp1 protein localized at the mitochondria, which is required for mitochondrial fission. In contrast, the punctate staining of Drp1 on mitochondrial tubules was decreased in GBP2overexpressed or IFN- $\gamma$-treated cells by $84 \%$ and $60 \%$, respectively (Figures $7 c$ and $d$, right panel). To determine whether decreased Drp1 at the mitochondria was due to upregulation of GBP2 expression, we transfected Flag-GBP2 (green) into MDA-MB-231 cells and performed immunostaining to detect the change in Drp1 translocation. As shown in Supplementary Figure $6 \mathrm{~b}$, the distribution of endogenous Drp1 (red) changed from partially localized within the mitochondria (white) to clustered and partially co-localized with GBP2 (green) and restricted in the cytoplasm, along with mitochondrial morphology changing from tubular to more filamentous, consistent with our other data.

To ascertain the effect of GBP2 on Drp1 translocation, we co-transfected GBP2 and Drp1 constructs into MCF-7 cells. We used MCF-7 cells because our previous study reported that Drp1 expression levels were low in nonmetastatic breast cancer cell lines, such as MCF-7 cells. ${ }^{17}$ Moreover, endogenous GBP2 expression was also low in MCF-7 cells (data not shown). Confocal images show that control cells have filamental mitochondria (Supplementary Figure 6c, left panel). Myc-tagged Drp1 expression (green) showed partial co-localization with mitochondria as puncta and induced mitochondrial fragmentation in cells. Interestingly, co-expression of Flag-tagged GBP2 changes the distribution of myc-tagged Drp1 (green). The majority of Drp1 was found to be co-localized with Flag-GBP2 (purple) near the edge of the cytoplasm with little on mitochondrial tubules (Supplementary Figure 6c, green panel). As expected, co-expression of GBP2 attenuated Drp1-induced fission of mitochondria (Supplementary Figure 6c, red panel).

Previous work revealed that mitochondrial fission directs mitochondrial accumulation to the lamellipodia region at the leading edge of cells. We speculate that the effect of GBP2 on Drp1 translocation also blocks mitochondrial accumulation at the leading edge of cells. As shown in Figures $7 e$ and $f$, mitochondrial localization changes during GBP2 upregulation were quantified, ${ }^{17}$ and overexpression of GBP2 or IFN- $\gamma$ treatment reduced mitochondrial accumulation in the lamellipodia region.

Collectively, our data indicate that GBP2 attenuates subcellular localization of Drp1 to mitochondria through interaction with Drp1 in the cytosol, suppressing mitochondrial fission and cell invasion.

\section{Discussion}

We previously reported that Drp1-dependent mitochondrial fission regulates breast cancer cell migration and invasion. ${ }^{17}$ In this study, GBP2 was found to bind directly to Drp1 and block Drp1 translocation from the cytoplasm to the mitochondria, which is a potential mechanism for reducing mitochondrial fission. The interaction between GBP2 and Drp1 was systematically and consistently confirmed under various experimental conditions using both ectopically and endogenously expressed proteins. As an IFN- $\gamma$-inducible protein, GBP2 belongs to the larger dynamin superfamily of GTPases that include, for instance, Dynamin and Mx. GBP2 can oligomerize with itself or with other GBPs. ${ }^{23}$ GBP2 was previously described to bind GBP1 and to polymerize around cytosolic bacteria to allow escape from cytosolic bacteria through autophagy. ${ }^{31}$ However, we demonstrate that Drp1, another kind of dynamin family protein, is a new target for GBP2. Despite limited sequence homology, GBP2 and Drp1 share similar biochemical features, ${ }^{29}$ such as the conserved GTPase domain. Moreover, the crystal structure of GBP ${ }^{32,33}$ intramolecular interactions was found to be similar to those that have been predicted for dynamins, such as assembled Drp1. It is possible that GBP2 and Drp1 bind to each other to form hetero-oligomers.

To be oligomerized, GBP family proteins first need the $\mathrm{N}$-terminal GTPase domains to self-dimerize, which requires GTPase activity. Enzymatic activity of GBP leads to a structural shift, making previously buried sites on the C-terminal domain available for further interaction. ${ }^{26,34}$ Thus GTPase activity is necessary for the oligomerization of GBP family proteins, as well as for dynamin superfamily proteins. ${ }^{27,26}$ In our study, two GTPase-defective mutants, $\mathrm{GBP}^{\mathrm{K} 51 \mathrm{~A}}$ and $\mathrm{GBP} \mathrm{D}^{\mathrm{D} 103 \mathrm{~L} / \mathrm{D} 108 \mathrm{~L}}$, have different effect on Drp1 binding. $\mathrm{GBP}^{\mathrm{K} 51 \mathrm{~A}}$ failed to interact with Drp1, while GBP2 ${ }^{\mathrm{D} 103 \mathrm{~L} / \mathrm{D} 108 \mathrm{~L}}$ could bind Drp1. As previously reported, GBP1 and GBP2 share $75 \%$ sequence homology and have the same domains for GTPase and dimerization. ${ }^{26}$ We can learn from GBP1 to study the function of GBP2. GBP2 ${ }^{\mathrm{K} 51 \mathrm{~A}}$ or $\mathrm{GBP} 1^{\mathrm{K} 51 \mathrm{~A}}$ mutant was reported to strongly decrease the affinity of all three mant-nucleotides (mant-GTP, mant-GDP and mant-GMP), indicating that the $\mathrm{GBP}^{\mathrm{K} 51 \mathrm{~A}}$ mutants will occur as predominantly nucleotide-free. ${ }^{35}$ Moreover, the GBP2 ${ }^{\mathrm{K} 51 \mathrm{~A}}$ mutant was constitutively monomeric, and the 

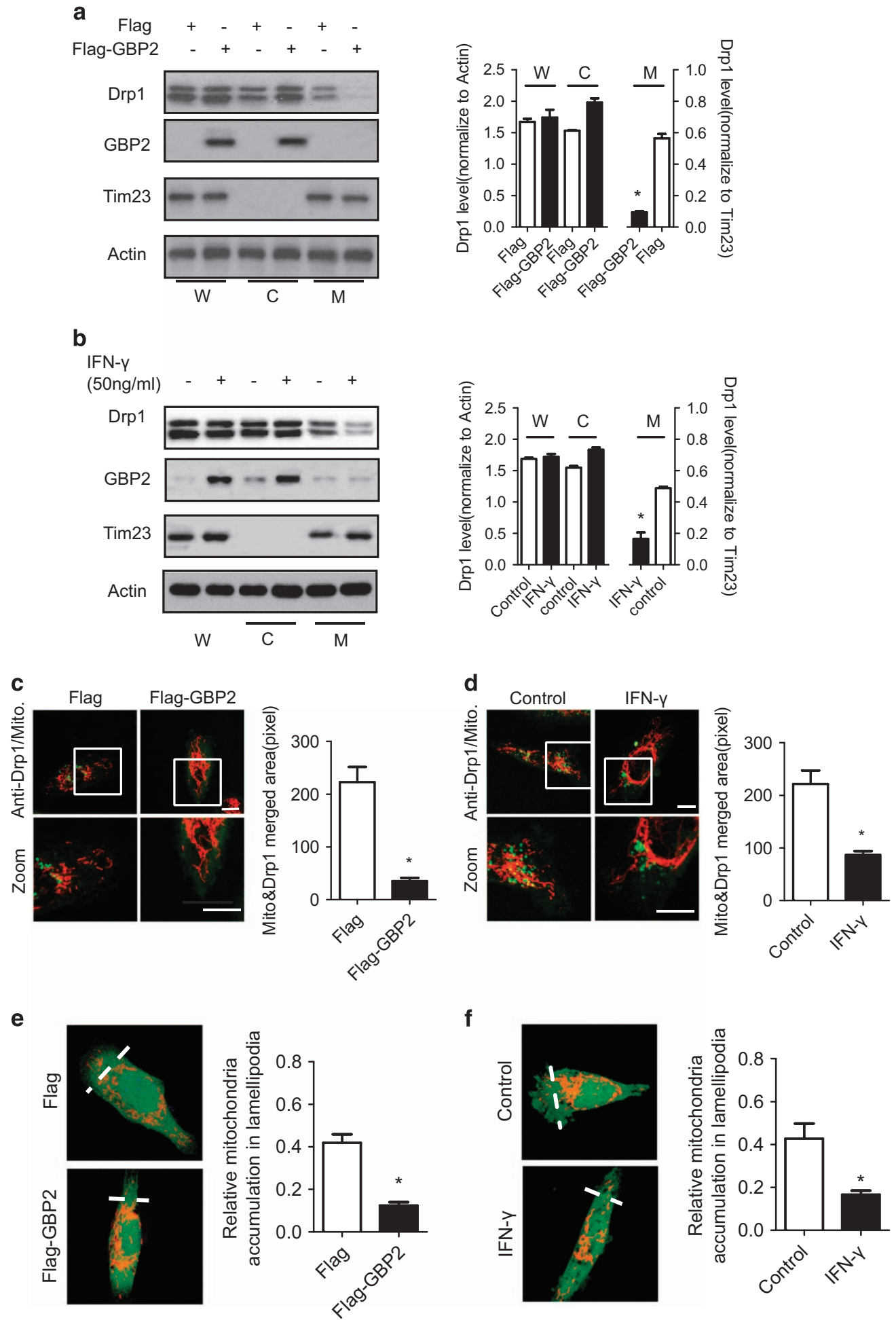

f

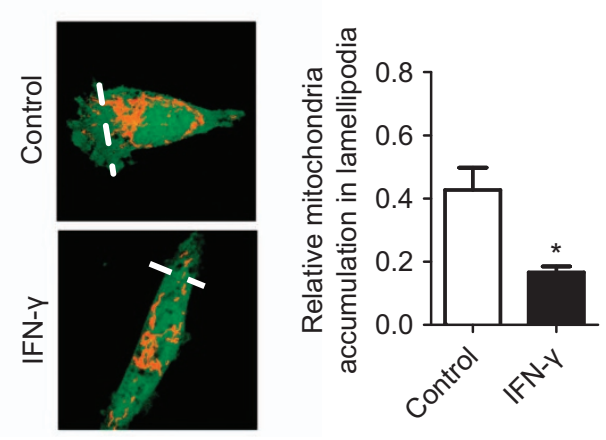

GTPase hydrolytic activity of $\mathrm{GBP} 2^{\mathrm{K} 51 \mathrm{~A}}$ mutant was negligible. ${ }^{35,36}$ GBP1 ${ }^{\text {D103L/D108L }}$ was a monomer with nucleotides. The double mutant could only hydrolyze GTP to GDP and lacked the second hydrolysis activity, suggesting that the $\mathrm{GBP}^{\mathrm{D} 103 \mathrm{~L} / \mathrm{D} 108 \mathrm{~L}}$ mutant could bind with GTP and GDP. ${ }^{26,28}$ Thus the GBP2 $2^{\mathrm{K} 51 \mathrm{~A}}$ and GBP2 $2^{\mathrm{D} 103 \mathrm{~L} / \mathrm{D} 108 \mathrm{~L}}$ mutants may have

two defects, differences in nucleotide affinity and hydrolytic activity. First, the GBP2 ${ }^{\mathrm{K} 51 \mathrm{~A}}$ mutant is nucleotide-free; GBP2 ${ }^{\mathrm{D} 103 \mathrm{~L} / \mathrm{D} 108}$ mutants are not and can bind with GTP and GDP. Second, GBP2 $2^{\mathrm{K} 51 \mathrm{~A}}$ has little GTP hydrolysis; the double mutants have only the first hydrolytic activity. It is noteworthy that the ${ }^{103}$ DXEKGD ${ }^{108}$ motif, including D103 and D108, is 
Figure 7 GBP2 blocks Drp1 translocation from cytosol to mitochondria and the distribution to lamellipodia. Western blotting analysis of distribution of Drp1 in the mitochondrial fraction in (a) MDA-MB-231 cells expressing Flag or Flag-tagged GBP2 or (b) cells pretreated without or with IFN- $\gamma(50 \mathrm{ng} / \mathrm{ml})$ for $48 \mathrm{~h}$. Equal amounts of protein of whole-cell lysate (W), cytosol (C) and mitochondrial (M) fractions were loaded on SDS-PAGE and analyzed by western blotting using anti-Drp1 and GBP2 antibodies. Right panel, Drp1 band density was measured and normalized to $\beta$-actin (W or $\mathrm{C}$ ) or Tim23 (M), Mean \pm s.e.m $(n=3)$. ${ }^{*} P<0.05$ between two groups. $\beta$-Actin was used as a loading control of whole cell lysate and cytosol fraction whereas Tim23 was used as the loading control of mitochondrial fraction. (c and d) Confocal microscopic images showing the subcellular distribution of endogenous Drp1 in MDA-MB-231 cells transfected with Flag-GBP2 or Flag protein (c) and MDA-MB-231 cells treated without or with IFN- $\gamma$ (d). Cells were stained with Mitotracker Red and then immuno-labelled with anti-Drp1 antibody (green). Scale bar, $10 \mu \mathrm{m}$. The histograms show the statistics of co-localization level of drp1 and mitochondria in panels (c and d). Data shown are mean \pm S.E.M., ${ }^{*} P<0.05, n=18-25$ randomly selected cells. (e and f) Upregulation of GBP2 block mitochondrial distribution to lamellipodia in MDA-MB-231 cells induced by Chemoattractant NIH-3T3 CM. MDA-MB-231 cells stained with MitoTracker Red and CellTracker Green were visualized with a confocal microscope and the integrated fluorescent intensity was analyzed by the Image-Pro Plus software. The relative abundance of mitochondria in the lamellipodia region was calculated as described in Materials and Methods. Columns, means; bar, S.E.M. ${ }^{*} P<0.05 . n=45-52$ randomly selected cells

located at the dimeric interface of GBP1, and the D103 and D108 residues have not been reported to interact in dimerization of GBP1. ${ }^{28,37}$ Furthermore, the ${ }^{103}$ DXEKGD ${ }^{108}$ motif of GBP1 is unique for GBP family proteins and not found in other GTP-binding proteins. ${ }^{26}$ These reports indicated the K51 residue is more important for the dimerization of different groups of dynamin proteins. After all, immunofluorescence assays revealed that the $\mathrm{GBP} 2^{\mathrm{K} 51 \mathrm{~A}}$ mutant was distributed evenly in the cytoplasm, which is consistent with a previous report, ${ }^{27}$ whereas GBP2 wild type or GBP2 ${ }^{\mathrm{D} 103 \mathrm{~L} / \mathrm{D} 108 \mathrm{~L}}$ mutant was distributed with granular accumulation in the cytosol. These results further suggest that K51 and the ${ }^{103}$ DXEKGD ${ }^{108}$ motifs have different roles in GBP2's interaction with Drp1.

A recent study revealed that high GBP2 is associated with better prognosis in breast cancer, particularly in quickly proliferating tumors. ${ }^{12}$ Further testing predicted that GBP2 correlates with T-cell signature, indicating tumor infiltration with $T$ cells. In our study, we demonstrated that upregulation of GBP2 expression suppresses metastasis in breast cancer cells by inhibiting Drp-1-dependent mitochondrial fission, providing further understanding of the role and mechanism of GBP2 in breast cancer. We used MDA-MB-231, MDAMB-436 (estrogen receptor (ER) negative, metastatic) and MCF-7 (ER positive, non-metastatic) cells ${ }^{17,38}$ for our in vitro models. Drp1 expression is high in metastatic breast cancer, and clinical findings have demonstrated that ER-negative carcinomas usually proliferate faster ${ }^{12}$ and are more inclined to nodal metastasis than are ER-positive neoplasms. ${ }^{39}$ Thus high Drp1 expression in breast tumors may be promoting high rates of proliferation and metastasis. High GBP2 expression could inhibit Drp1-mediated breast cancer invasion and reduce the risk of tumor recurrence. After all, the risk of recurrence in patients with ER-negative primary cancer is higher than that in ER-positive tumors. ${ }^{12}$ Because there are many subtypes of breast cancer based on ER, HER and PR status, we still need to determine the expression and role of GBP2 and Drp1 in additional cancer specimens to determine whether the role of GBP2 and Drp1 in metastasis and tumorigenesis is conserved in other breast cancer subtypes.

We next tested increased GBP2 levels to determine the function in breast cancer cells with low GBP2 expression and found that exogenous GBP2 transfection led to a greater inhibition of metastasis in cells than did IFN- $\gamma$ treatment (Figure 1a,Figure 2a). This data supports the finding that high GBP2 levels are associated with improved metastasis-free survival in node-negative breast carcinomas. ${ }^{12}$ It should be noted that increasing IFN- $\gamma$ concentration failed to further increase GBP2 expression in cells (Supplementary Figure 7b) but increased expression of other proteins that promote breast cancer metastasis. ${ }^{40}$ This may provide an additional explanation for why IFN- $\gamma$ is not an efficient breast cancer therapy. Thus targeting GBP2, an IFN- $\gamma$ inducible protein, represents a novel approach for suppressing breast cancer invasion.

In conclusion, out data show for the first time that GBP2 directly interacts with Drp1, and we identify GBP2 as an inhibitory factor in breast cancer metastasis. Our data suggest that upregulation of GBP2 expression, a key step to block Drp1-dependent mitochondrial fission, may represent a novel strategy to prevent metastasis in breast cancers.

\section{Materials and Methods}

Cell culture and transfection. All cell lines were from the American Type Culture Collection (ATCC, Manassas, VA, USA). Human metastatic breast cancer lines MDA-MB-231, MDA-MB-436 and mouse embryonic NIH-3T3 fibroblasts were cultured in DMEM with $10 \%$ fetal bovine serum (FBS). Human non-metastatic breast cancer MCF7 cells were cultured in IMEM, $10 \%$ FBS and $10 \mu \mathrm{g} / \mathrm{ml}$ insulin. Plasmids were transfected into cells using Amaxa Nucleofector Kits (Lonza Inc., Allendale, NJ, USA), and cells harvested $24 \mathrm{~h}$ after transfection were subjected to western blotting analysis and Transwell invasion assays. Transfection efficiency with the control GFP vector system was approximately $70 \%$.

Plasmid construction and RNAi. Plasmids encoding c-myc-tagged or GFP-Drp1 were gifts from Dr. Quan Chen (Institute of Zoology, Chinese Academy of Sciences, Beijing, China). Drp1 was inserted in pECFP-N1 using EcoRI and BamHI. The GBP2 construct cloned from a human fetal liver CDNA library was inserted into the vector pGEX-6P1 (GE Healthcare, Princeton, NJ, USA) to generate pGST-GBP2 using BamHI and Nott. This construct was also inserted into the vector pFLAGCMV-4 (Sigma, St. Louis, MO, USA) to generate pFLAG-GBP2 using Bgll and Kpnl and inserted into pEGFP-C2 and pEYFP-C1 (Clontech, Palo Alto, CA, USA) to generate pEGFP-GBP2 or pEYFP-GBP2 using Kpnl and BamHI, respectively. The GBP1 construct purchased from GeneCopoeia Company was inserted into the pFLAG-CMV-4 vector (Sigma) to generate pFLAG-GBP1 using EcoRl and BamHI. The GBP2 mutant was generated by site-directed mutagenesis using Pfu-ultra poly-merase (Stratagene, La Jolla, CA, USA) followed by Dpnl digestion (Fermentas Inc., Glen Burnie, MD, USA) according to the manufacturer's instructions. Small interfering RNA (siRNA) oligonucleotides were purchased from Dharmacon (Lafayette, CO, USA) with sequences targeting GBP2 (5'-GGA GGUUACCGUCUCUUUA-3') GBP1 (5'-AGGCAUGUACCAUAAGCUA-3') or Drp1 (5'-ACUAUUGAAGGAACUGCAAAAUAUA-dAdG-3'). For GBP2, GBP1 or Drp1 shRNA construction, the siRNA was cloned into the pSilencer 2.1-U6 hygro plasmid. The vector expressing GBP2, GBP1, Drp1 shRNA or its scramble were transiently transfected into cells using the Amaxa Nucleofector Kit. Cells were treated with IFN- $\gamma(50 \mathrm{ng} / \mathrm{ml})$ and harvested after $48 \mathrm{~h}$ for western blotting analysis and Transwell invasion assays. The siRNA-insensitive mutant of GFP-Drp1 was constructed as described previously. ${ }^{17}$

Antibodies and reagents. Antibodies of Drp1 and Tim23 were purchased from Becton Dickinson (San Jose, CA, USA). Antibodies for Drp1 Ser 637 and Ser 616 were from Cell Signaling Technology Inc. (Beverly, MA, USA). Antibodies for Mfn1, Flag and $\beta$-actin were from Sigma. The GST antibody was from Novagen (Madison, WI, USA), and the Mfn2 antibody was from Abnova (Taipei, Taiwan). 
Antibodies for GBP2 and GBP1 were from Sigma. Antibodies were diluted 1:100 from the stock concentration for immunostaining and $1: 1000-1: 5000$ for western blotting. The recombinant human IFN- $\gamma$ was from PeproTech (Rocky Hill, NJ, USA), U0126 was from Cell Signaling Technology. MitoTracker Red and Alexa Fluor 647-, Rhodamine- or fluorescein isothiocyanate (FITC)-conjugated second antibodies were purchased from Invitrogen (Carlsbad, CA, USA).

GST pull-down assay. GST-tagged GBP2 or GST control was expressed in Escherichia coli BL21 (DE3) strain under induction of $1 \mathrm{mM}$ isopropyl- $\beta$-Dthiogalactopyranoside. The GST-GBP2 and GST protein were purified using GSTbind resin (Novagen) according to manufacturer's instructions. GST or GST-GBP2 bound to resins was incubated with MDA-MB-231 cell lysate overnight and was then extensively washed with RIPA buffer. Cellular proteins bound to GST or GST-GBP2 were analyzed by SDS-PAGE. Expressed GST protein was used as a control. SDSPAGE gels were stained using a ProteoSilver Plus Silver Stain Kit (Sigma-Aldrich, St. Louis, MO, USA) according to the manufacturer's instructions. Bands appearing specifically in the GST-GBP2 precipitate were excised for mass spectrometry.

Mass spectrometric analysis. All NanoLC-MS/MS analyses were performed on a nanoLC-LTQ-Orbitrap XL mass spectrometer (Thermo, San Jose, CA, USA) at a resolution of 60000 . Solvents used were $0.5 \%$ formic acid water solution (buffer A) and $0.5 \%$ formic acid acetonitrile solution (buffer B). Trapping was performed at $2 \mu / \mathrm{min}$ in buffer $A$ for $15 \mathrm{~min}$, and elution was achieved with a gradient of $0-32 \%$ in buffer B for $80 \mathrm{~min}, 32-50 \%$ buffer B for $6 \mathrm{~min}, 80 \%$ buffer B for $6 \mathrm{~min}$ at a flow rate of $300 \mathrm{nl} / \mathrm{min}$. Eluted peptide cations were converted to gasphase ions using Nanospray Flex ion source at $2.0 \mathrm{kV}$. Raw data were processed using Proteome Discoverer (version 1.4.0.288, Thermo Fischer Scientific, Waltham, MA, USA). MS 2 spectra were queried with the SEQUEST engine against the uniprot human complete proteome database. Database searches were performed with the following parameters: precursor mass tolerance 20 ppm; MS/MS mass tolerance $0.6 \mathrm{Da}$; two missed cleavage for tryptic peptides; variable modifications oxidation (M), Methylthio (C), and biotin-maleimide (C). Peptide spectral matches were validated by a targeted decoy database search at a $1 \%$ false discovery rate. With proteome Discoverer, peptide identifications were grouped into proteins according to the law of parsimony.

Immunofluorescence and confocal microscopy. Cells on coverslips were fixed with $4 \%$ paraformaldehyde in PBS, permeabilized with $0.1 \%$ Triton $\mathrm{X}-100$, blocked with $1 \% \mathrm{BSA}$ and $10 \%$ horse serum and incubated with primary antibodies and Rhodamine- or FITC-conjugated secondary antibodies. MitoTracker Red ( $50 \mathrm{nM}$; Invitrogen) was used for mitochondrial staining. Images were visualized with an Olympus FV1000 confocal microscope (Olympus, Tokyo, Japan) and processed using the Fluoview software (Olympus). Mitochondrial length and Drp1 localized at mitochondria were measured as described ${ }^{20}$ before using the Image-Pro Plus software (Media Cybernetics, Rockville, MD, USA). The relative abundance of mitochondria in the lamellipodia region was calculated by using the method described before. ${ }^{17}$

Transwell invasion assays. Matrigel invasion assays were carried out at $37^{\circ} \mathrm{C}$ for $16 \mathrm{~h}$ using 24-well Transwell inserts (Corning-Costar, Cambridge, MA, USA) coated with $30 \mu \mathrm{g}$ of Matrigel (BD Biosciences, San Jose, CA, USA). Cells $(50000)$ suspended in $200 \mu \mathrm{l}$ of serum-free medium were seeded into the upper chamber and $600 \mu \mathrm{l}$ of $\mathrm{NIH}-3 \mathrm{~T} 3 \mathrm{CM}$ were placed in the lower chamber. Cells that invaded through the membrane were counted and normalized relative to 10000 seeded cells. CM from NIH-3T3 cells was collected and used as a chemoattractant as previously reported. ${ }^{17}$

In vivo tumor xenograft experiments. MDA-MB-231 cells were stably transfected with GFP, GFP-GBP2, scramble shRNA or Drp1 shRNA vector, and then transfected cells $\left(1.0 \times 10^{6}\right)$ were injected into the tail vein of 6-8-week-old female athymic nude BALB/c mice. Six weeks later, mice were killed, and the incidence and number of visible lung metastases were recorded. The lungs were dissected, rinsed in PBS and fixed in Bouin's solution (picric acid: formaldehyde: acetic acid, $15: 5: 1)$, followed by paraffin embedding and sectioning (5- $\mu \mathrm{m}$ thick), stained with hematoxylin and eosin and scanned using a TissueGnostics TissueFAXS Cytometry instrument (TissueGnostics GmbH, Vienna, Austria) to quantify the number of metastatic nodules. All studies involving mice were approved by the Institutional Animal Care and Treatment Committee of Sichuan University.
FRET assays. All FRET assays were performed using an Olympus FV1000 confocal laser scanning microscope $24 \mathrm{~h}$ after cells were transfected. The donor (CFP) was excited at $458 \mathrm{~nm}$, and its fluorescence was detected at $478-498 \mathrm{~nm}$ (CFP channel), whereas excitation at $514 \mathrm{~nm}$ and emission at $545 \pm 15 \mathrm{~nm}$ were used for detecting the acceptor (YFP) (YFP channel). FRET was detected at an excitation of $458 \mathrm{~nm}$ and emission of $545 \pm 15 \mathrm{~nm}$ (FRET channel). Fluorescence images of the transfected cells were taken at the CFP, YFP and FRET channels sequentially. Dequenching of the donor fluorescence by photobleaching of the acceptor YFP was performed by illuminating the transfected cells at $514 \mathrm{~nm}$ for 250 iterations, and then CFP-Drp1 images were taken in the same focal plane. The FRET efficiency was calculated using the equation $E=1-(F D A / F D)$, where FDA and $F D$ are the fluorescence intensity of CFP in the cells expressing both donor and acceptor and donor alone (acceptor was quenched), respectively.

Immunoprecipitation. Cells were collected and washed twice with PBS and re-suspended in lysis buffer $(0.75 \mathrm{M}$ aminocaproic acid, $50 \mathrm{mM}$ Bis-Tris, $\mathrm{pH} 7.0$, $1.5 \% \mathrm{n}$-dodecyl-b-d-maltopyranoside, $1 \mathrm{mM}$ phenylmethyl sulfonyl fluoride, $1 \mathrm{mg} / \mathrm{ml}$ leutpeptin and $1 \mathrm{mg} / \mathrm{ml}$ pepstatin) for $30 \mathrm{~min}$ on ice. Then samples were centrifuged at $72000 \times \mathrm{g}$ for $20 \mathrm{~min}$ at $4{ }^{\circ} \mathrm{C}$. The primary monoclonal antibody $(2 \mu \mathrm{g})$ was added into the supernatant containing $500 \mu \mathrm{g}$ protein and incubated at $4{ }^{\circ} \mathrm{C}$ overnight. After incubation with Protein G-agarose (Millipore, Boston, MA, USA) for $2 \mathrm{~h}$ at $4^{\circ} \mathrm{C}$, the beads were washed three times with lysis buffer and boiled with loading buffer for $5 \mathrm{~min}$. Proteins were separated by SDS-polyacrylamide gel electrophoresis, and western blotting was performed with the indicated antibodies.

Cellular fractionation. Cells were fractionated by differential centrifugation as described previously. ${ }^{41-43}$ Briefly, cells were harvested and resuspended in three volumes of hypotonic buffer (210 mM sucrose, $70 \mathrm{mM}$ mannitol, $10 \mathrm{mM}$ Hepes, $\mathrm{pH}$ 7.4, $1 \mathrm{mM}$ EDTA) containing $1 \mathrm{mM}$ phenylmethylsulfonyl fluoride, $50 \mathrm{mg} / \mathrm{ml}$ trypsin inhibitor, $10 \mathrm{mg} / \mathrm{ml}$ leupeptin, $5 \mathrm{mg} / \mathrm{ml}$ aprotinin and $10 \mathrm{mg} / \mathrm{ml}$ pepstatin. After gentle homogenization with a Dounce homogenizer (Kontes, Vineland, NJ, USA), the cell lysates were centrifuged at $1000 \times g$ for 5 min to remove unbroken cells and nuclei. The supernatant was collected and centrifuged at $10000 \times g$ to pellet the mitochondria-enriched heavy membrane fraction. The supernatant was further centrifuged at $100000 \times g$ to obtain the cytosolic fraction.

Assay of cell viability and death. Cell viability was determined by CellTiter-Glo Luminescent Cell Viability Assay from Promega (Madison, WI, USA) as described. ${ }^{44,45}$ Apoptosis was analyzed using the Annexin $V$ Apoptosis Kit (Calbiochem, Gibbstown, NJ, USA ). Briefly, cells were harvested and re-suspended at a concentration of $1.0 \times 10^{6}$ cells per $\mathrm{ml}$ and stained with FITC-labeled annexin V and propidium iodide as described. ${ }^{17,46}$

Statistical analysis. Results are expressed as the mean \pm S.E.M. of at least three independent experiments, and statistical comparisons were made using Student's $t$-test or two-way ANOVA with Bonferroni correction where there were multiple comparisons. $P<0.05$ was considered to be statistically significant.

\section{Conflict of Interest}

The authors declare no conflict of interest.

Acknowledgements. The work was supported by Natural Science Foundation of China (NSFC)-81773188, 81760557, 81703081 and Program for New Century Excellent Talents in University (NCET)-12-0381.

\section{Publisher's Note}

Springer Nature remains neutral with regard to jurisdictional claims in published maps and institutional affiliations.

1. Cheng $\mathrm{Y}$, Colonno RJ, Yin FH. Interferon induction of fibroblast proteins with guanylate binding activity. J Biol Chem 1983; 258: 7746-7750.

2. Vestal DJ, Jeyaratnam JA. The guanylate-binding proteins: emerging insights into the biochemical properties and functions of this family of large interferon-induced guanosine triphosphatase. J Interferon Cytokine Res 2011; 31: 89-97.

3. Olszewski MA, Gray J, Vestal DJ. In silico genomic analysis of the human and murine guanylatebinding protein (GBP) gene clusters. J Interferon Cytokine Res 2006; 26: 328-352. 
4. Weinlander $\mathrm{K}$, Naschberger $\mathrm{E}$, Lehmann $\mathrm{MH}$, Tripal $\mathrm{P}$, Paster $\mathrm{W}$, Stockinger $\mathrm{H}$ et al. Guanylate binding protein-1 inhibits spreading and migration of endothelial cells through induction of integrin alpha4 expression. FASEB J 2008; 22: 4168-4178.

5. Britzen-Laurent N, Lipnik K, Ocker M, Naschberger E, Schellerer VS, Croner RS et al. GBP-1 acts as a tumor suppressor in colorectal cancer cells. Carcinogenesis 2013; 34: 153-162.

6. Lipnik K, Naschberger E, Gonin-Laurent N, Kodajova P, Petznek H, Rungaldier S et al. Interferon gamma-induced human guanylate binding protein 1 inhibits mammary tumor growth in mice. Mol Med 2010; 16: 177-187.

7. Capaldo CT, Beeman N, Hilgarth RS, Nava P, Louis NA, Naschberger E et al. IFN-gamma and TNF-alpha-induced GBP-1 inhibits epithelial cell proliferation through suppression of beta-catenin/TCF signaling. Mucosal Immunol 2012; 5: 681-690.

8. Guenzi E, Töpolt K, Lubeseder-Martellato C, Jörg A, Naschberger E, Benelli R et al. The guanylate binding protein-1 GTPase controls the invasive and angiogenic capability of endothelial cells through inhibition of MMP-1 expression. EMBO J 2003; 22: 3772-3782.

9. Cancer Genome Atlas N, Comprehensive molecular characterization of human colon and rectal cancer. Nature 2012; 487: 330-337.

10. Messmer-Blust AF, Balasubramanian S, Gorbacheva VY, Jeyaratnam JA, Vestal DJ. The interferon-gamma-induced murine guanylate-binding protein-2 inhibits rac activation during cell spreading on fibronectin and after platelet-derived growth factor treatment: role for phosphatidylinositol 3-kinase. Mol Biol Cell 2010; 21: 2514-2528.

11. Gorbacheva VY, Lindner D, Sen GC, Vestal DJ. The interferon (IFN)-induced GTPase, mGBP-2. Role in IFN-gamma-induced murine fibroblast proliferation. J Biol Chem 2002; 277: 6080-6087.

12. Godoy $P$, Cadenas $C$, Hellwig B, Marchan R, Stewart J, Reif R et al. Interferon-inducible guanylate binding protein (GBP2) is associated with better prognosis in breast cancer and indicates an efficient T cell response. Breast Cancer 2014; 21: 491-499.

13. Balasubramanian S, Fan M, Messmer-Blust AF, Yang $\mathrm{CH}$, Trendel JA, Jeyaratnam JA et al. The interferon-gamma-induced GTPase, mGBP-2, inhibits tumor necrosis factor alpha (TNFalpha) induction of matrix metalloproteinase-9 (MMP-9) by inhibiting NF-kappaB and Rac protein. J Biol Chem 2011; 286: 20054-20064.

14. Westermann B. Mitochondrial fusion and fission in cell life and death. Nat Rev Mol Cell Biol 2010; 11: 872-884.

15. Chan DC. Dissecting mitochondrial fusion. Dev Cell 2006; 11: 592-594.

16. Grandemange S, Herzig S, Martinou JC. Mitochondrial dynamics and cancer. Semin Cancer Biol 2009; 19: 50-56.

17. Zhao J, Zhang J, Yu M, Xie Y, Huang Y, Wolff DW et al. Mitochondrial dynamics regulates migration and invasion of breast cancer cells. Oncogene 2013; 32: 4814-4824.

18. Albini A, Benelli R. The chemoinvasion assay: a method to assess tumor and endothelial cell invasion and its modulation. Nat Protoc 2007; 2: 504-511.

19. Vestal DJ, Gorbacheva VY, Sen GC. Different subcellular localizations for the related interferon-induced GTPases, MuGBP-1 and MuGBP-2: implications for different functions? $J$ Interferon Cytokine Res 2000; 20: 991-1000.

20. Zhang J, Liu W, Liu J, Xiao W, Liu L, Jiang C et al. G-protein beta2 subunit interacts with mitofusin 1 to regulate mitochondrial fusion. Nat Commun 2010; 1: 101.

21. Cribbs JT, Strack S. Reversible phosphorylation of Drp1 by cyclic AMP-dependent protein kinase and calcineurin regulates mitochondrial fission and cell death. EMBO Rep 2007; 8 : 939-944.

22. Chang CR, Blackstone C. Cyclic AMP-dependent protein kinase phosphorylation of Drp1 regulates its GTPase activity and mitochondrial morphology. J Biol Chem 2007; 282 21583-21587.

23. Serasinghe MN, Wieder SY, Renault TT, Elkholi R, Asciolla JJ, Yao JL et al. Mitochondrial division is requisite to RAS-induced transformation and targeted by oncogenic MAPK pathway inhibitors. Mol Cell 2015; 57: 521-536.

24. Kashatus JA, Nascimento A, Myers LJ, Sher A, Byrne FL, Hoehn KL et al. Erk2 phosphorylation of Drp1 promotes mitochondrial fission and MAPK-driven tumor growth. $\mathrm{Mol}$ Cell 2015; 57: 537-551

25. Cassidy-Stone A, Chipuk JE, Ingerman E, Song C, Yoo C, Kuwana T et al. Chemica inhibition of the mitochondrial division dynamin reveals its role in Bax/Bak-dependent mitochondrial outer membrane permeabilization. Dev Cell 2008; 14: 193-204.

26. Abdullah N, Balakumari M, Sau AK. Dimerization and its role in GMP formation by human guanylate binding proteins. Biophys J 2010; 99: 2235-2244.

27. Britzen-Laurent N, Bauer M, Berton V, Fischer N, Syguda A, Reipschläger S et al. Intracellular trafficking of guanylate-binding proteins is regulated by heterodimerization in a hierarchical manner. PLOS ONE 2010; 5: e14246-e14246.

28. Abdullah N, Srinivasan B, Modiano N, Cresswell P, Sau AK. Role of individual domains and identification of internal gap in human guanylate binding protein-1. J Mol Biol 2009; 386: 690-703.
29. Praefcke GJ, McMahon HT. The dynamin superfamily: universal membrane tubulation and fission molecules? Nat Rev Mol Cell Biol 2004; 5: 133-147.

30. Smirnova E, Griparic L, Shurland D-L, Van Der Bliek AM. Dynamin-related protein Drp1 is required for mitochondrial division in mammalian cells. Mol Biol Cell 2001; 12: 2245-2256.

31. MacMicking JD. Interferon-inducible effector mechanisms in cell-autonomous immunity. Nat Rev Immunol 2012; 12: 367-382.

32. Prakash B, Praefcke GJ, Renault L, Wittinghofer A, Herrmann C. Structure of human guanylate-binding protein 1 representing a unique class of GTP-binding proteins. Nature 2000; 403: 567-571.

33. Prakash B, Renault L, Praefcke GJ, Herrmann C, Wittinghofer A. Triphosphate structure of guanylate-binding protein 1 and implications for nucleotide binding and GTPase mechanism. EMBO J 2000; 19: 4555-4564

34. Syguda A, Bauer M, Benscheid U, Ostler N, Naschberger E, Ince S et al. Tetramerization of human guanylate-binding protein 1 is mediated by coiled-coil formation of the $\mathrm{C}$-terminal $\alpha$ helices. FEBS J 2012; 279: 2544-2554.

35. Kravets E, Degrandi D, Weidtkamp-Peters S, Ries B, Konermann C, Felekyan S et al. The GTPase activity of murine guanylate-binding protein 2 (mGBP2) controls the intracellular localization and recruitment to the parasitophorous vacuole of Toxoplasma gondii. J Biol Chem 2012; 287: 27452-27466.

36. Praefcke GJ, Kloep S, Benscheid U, Lilie H, Prakash B, Herrmann C. Identification of residues in the human guanylate-binding protein 1 critical for nucleotide binding and cooperative GTP hydrolysis. J Mol Biol 2004; 344: 257-269.

37. Ghosh A, Praefcke GJ, Renault L, Wittinghofer A, Herrmann C. How guanylate-binding proteins achieve assembly-stimulated processive cleavage of GTP to GMP. Nature 2006 440: 101-104.

38. Elgamal OA, Park J-K, Gusev Y, Azevedo-Pouly ACP, Jiang J, Roopra A et al. Tumor suppressive function of mir-205 in breast cancer is linked to HMGB3 regulation. PLOS ONE 2013; 8: e76402.

39. Parl FF, Schmidt BP, Dupont WD, Wagner RK. Prognostic significance of estrogen receptor status in breast cancer in relation to tumor stage, axillary node metastasis, and histopathologic grading. Cancer 1984; 54: 2237-2242.

40. Payne KK, Manjili MH. Adaptive immune responses associated with breast cancer relapse. Arch Immunol Ther Exp (Warsz) 2012; 60: 345-350.

41. Guo W, Zhang Y, Ling Z, Liu X, Zhao X, Yuan Z et al. Caspase-3 feedback loop enhances Bid-induced AlF/endoG and Bak activation in Bax and p53-independent manner. Cell Death Dis 2015; 6: e1919.

42. Nie $\mathrm{C}$, Luo $\mathrm{Y}$, Zhao X, Luo N, Tong A, Liu X et al. Caspase-9 mediates Puma activation in UCN-01-induced apoptosis. Cell Death Dis 2014; 5: e1495.

43. Wang J, Guo W, Zhou H, Luo N, Nie C, Zhao X et al. Mitochondrial p53 phosphorylation induces Bak-mediated and caspase-independent cell death. Oncotarget 2015; 6 : 17192-17205.

44. Katayama R, Khan TM, Benes C, Lifshits E, Ebi H, Rivera VM et al. Therapeutic strategies to overcome crizotinib resistance in non-small cell lung cancers harboring the fusion oncogene EML4-ALK. Proc Natl Acad Sci 2011; 108: 7535-7540.

45. Bivona TG, Hieronymus H, Parker J, Chang K, Taron M, Rosell R et al. FAS and NF-[kgr] B signalling modulate dependence of lung cancers on mutant EGFR. Nature 2011; 471 $523-526$

46. Shen W, Du R, Li J, Luo X, Zhao S, Chang A et al. TIFA suppresses hepatocellula carcinoma progression via MALT1-dependent and-independent signaling pathways. Signal Transduct Targeted Ther 2016; 1: 16013

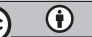

Cell Death and Disease is an open-access journal published by Nature Publishing Group. This work is licensed under a Creative Commons Attribution 4.0 International License. The images or other third party material in this article are included in the article's Creative Commons license, unless indicated otherwise in the credit line; if the material is not included under the Creative Commons license, users will need to obtain permission from the license holder to reproduce the material. To view a copy of this license, visit http://creativecommons.org/licenses/by/4.0/

(C) The Author(s) 2017 